\title{
The Effect of Silence on Tinnitus Perception
}

By: DENISE A. TUCKER, PHD, SUSAN L. PHILLIPS, PHD, ROGER A. RUTH, PHD, WINDY A. CLAYTON, MA, EDEN ROYSTER, MA, and ALLISON D. TODD, MA

Tucker, D.A., Phillips, S.L., Ruth, R.A., Clayton, W.A., Royster, E., Todd, A.D. (2005). The effect of silence on tinnitus perception. Otolaryngology-Head \& Neck Surgery. 132(1), 20-24

Made available courtesy of ELSEVIER:

http://www.journals.elsevierhealth.com/periodicals/ymhn

***Note: Figures may be missing from this format of the document

\begin{abstract}
:
OBJECTIVE: The effect of sustained silence was studied on the emergence of tinnitus perception in 120 normal hearing young adult Caucasians and African Americans.
\end{abstract}

STUDY DESIGN AND SETTING: After sitting in a sound booth for a period of 20 minutes, participants were asked to complete a questionnaire documenting whether they perceived sounds in the silent setting and descriptions of the sounds they heard.

RESULTS: Tinnitus-like sounds were perceived in $64 \%$ of listeners overall. No significant differences in tinnitus perception were observed between males and females. However, there was a significant difference in tinnitus perception between Caucasian and African American subjects, with tinnitus sounds emerging in sustained silence less frequently in African American listeners. Tinnitus emerged quickly in a majority of subjects (less than 4 minutes) and African American subjects who perceived tinnitus heard a greater number of individual tinnitus-like sounds than did Caucasian subjects. Ring (57\%), buzz (21\%), pulse (22\%), heartbeat (21\%), and hum (14\%) were the most common sounds heard, with ring being the most common overall tinnitus perception.

CONCLUSIONS AND SIGNIFICANCE: Few investigators have documented at the emergence of tinnitus in normal hearing subjects. Results of the current study found significant differences in tinnitus perception between Caucasian and African American subjects, but found no significant differences when comparing males and female subjects. EBM rating: C. (Otolaryngol Head Neck Surg 2005;132:20-4.)

\section{Article:}

For many people, tinnitus (ringing in the ear) is a common and fleeting experience. However, for more than 12 million Americans, the experience is a chronic condition that can severely impact the quality of life. ${ }^{1,2}$ The debilitating effects of chronic tinnitus can include significant sleep disorder, anxiety, and depression. ${ }^{3-5}$ Although the exact cause of tinnitus is not known, researchers point to mechanisms in both the auditory periphery ${ }^{6,7}$ and the central auditory system. ${ }^{8}$ To date, there is no medical cure for tinnitus. However, patients suffering with severe tinnitus can find relief and comfort from their symptoms through tinnitus management protocols. 
One of the more effective tinnitus management programs currently being utilized by audiologists and hearing specialists is Tinnitus Retraining Therapy (TRT), which employs a combination of audiologic testing, directive counseling, and the use of sound therapy to treat tinnitus patients. ${ }^{9,10}$ A core principle of the TRT program is the recommendation to avoid silence. This recommendation is given to tinnitus patients for two reasons. First, the presence of sustained silence may have a direct effect on the functioning and neuronal organization of the central auditory nervous system. This phenomenon may be evidenced in the significant and sometimes rapid and reversible changes observed in the auditory system resulting from sensory deprivation due to conductive and/or sensory hearing loss. ${ }^{7,11-13}$ Secondly, the perception of tinnitus is increased in silence as a result of the lack of any other environmental masking sound. In fact, it is widely believed that most normal- hearing individuals, when placed in silence for a period of time, will begin to hear tinnitus. ${ }^{14}$

Few studies have further examined the general effect of silence on the perception of tinnitus in normal listeners since the original Heller and Bergman study. Additionally, the Heller and Bergman study did not specifically sort out the effects of race and gender on tinnitus perception.

Cooper, ${ }^{15}$ in reviewing the Health and Nutrition Examination Survey of 1971-1975, reported that bothersome tinnitus did vary due to race and gender, with tinnitus being worse in African Americans. However, it has been our personal observation that tinnitus patients coming to our UNCG Tinnitus Clinic for Tinnitus Retraining Therapy have been predominantly Caucasian. The purpose of the present study is to further investigate the effect of silence on the perception of tinnitus in normal hearing young adults and to control for the variables of race and gender. We hypothesized there would be significant differences in tinnitus perception due to race and gender.

\section{METHODS}

\section{Participants}

A group of 120 normal-hearing adults between the ages of 18 and 30 years participated in the study. The subject pool consisted of 60 males and 60 females. Within both gender groups, 40 participants were Caucasian and 20 participants were African American. All participants were volunteers from the student body of the University of North Carolina Greensboro and from the Greensboro community, and approval for the study was obtained by the UNCG University Institutional Review Board. All participants had normal hearing sensitivity and no history of head trauma, neurological disease, or ear surgery. All participants were required to pass a hearing screening at $20 \mathrm{~dB}$ HL for both ears for octave frequencies between 250 and $8000 \mathrm{HZ}$. Additionally, each subject was examined using otoscopy and was required to pass a tympanogrametric screening to indicate normal middle ear function. Any subject with an abnormal tympanogram (negative pressure greater than $-100 \mathrm{daPa}$ or poor mobility) or with outer ear abnormalities (such as earwax or abnormal tympanic membrane) was excluded from participating in the study.

\section{Instrumentation}

Peripheral hearing sensitivity was assessed using the Grason-Stadler (GSI) 61 Clinical Audiometer and TDH-50 (ANSI 1996), and middle ear function was assessed using the GSI TympStar Middle Ear AnalyZer. Middle ear measurements were made outside the test booth. Pure tone hearing screening and tinnitus measures were obtained inside a double-walled test booth. 


\section{Procedures}

Ambient noise of the sound treated booth was measured using the Bruel and Kjaer (B\&K) 2203 sound level meter and a B\&K 1613 octave filter. Ambient noise levels of the sound treated booth were measured at ear level prior to the beginning of the study. The readings were within the accepted specifications of the ANSI S3.1 1977 Sound Room Ambient Noise standards. Ear level measurements in dB SPL were $24 \mathrm{~dB}$ at $125 \mathrm{HZ}, 15 \mathrm{~dB}$ at $250 \mathrm{HZ}, 6 \mathrm{~dB}$ at $500 \mathrm{HZ}, 12 \mathrm{~dB}$ at $1000 \mathrm{HZ}, 7 \mathrm{~dB}$ at $2000 \mathrm{HZ}, 7 \mathrm{~dB}$ at $4000 \mathrm{HZ}$, and $6 \mathrm{~dB}$ at $8000 \mathrm{HZ}$.

Once peripheral hearing was screened, each subject was seated in the sound booth and given instructions for the listening experiment. It is important to note that during the oral presentation and on the patient response form, the word "tinnitus" was not used so that the subject's perceptions and responses would not be biased. After the period of silence, each subject was given

\begin{tabular}{|c|c|c|c|}
\hline Population & $\begin{array}{c}\text { \# of Subject } \\
\text { hearing tinnitus }\end{array}$ & $\begin{array}{l}\text { Mean \# of } \\
\text { sounds }\end{array}$ & Mean fime \\
\hline Females & $64 \%(39 / 60)$ & 1.68 & $2 \min 56 \sec$ \\
\hline Males & $63 \%(38 / 60)$ & 1.61 & $1 \min 5 \mathrm{sec}$ \\
\hline Caucasians & $78 \%(62 / 80)$ & 1.44 & $2 \min 19 \sec$ \\
\hline $\begin{array}{l}\text { African } \\
\text { Americans }\end{array}$ & $38 \%(15 / 40)$ & 2.47 & $49 \mathrm{sec}$ \\
\hline $\begin{array}{r}\text { Caucasian } \\
\text { females }\end{array}$ & $78 \%(31 / 40)$ & 1.39 & $3 \min 19 \sec$ \\
\hline Caucasian males & $78 \%(31 / 40)$ & 1.55 & $1 \min 19 \sec$ \\
\hline $\begin{array}{l}\text { African American } \\
\text { females }\end{array}$ & $40 \%(8 / 20)$ & 3 & $1 \min 11 \mathrm{sec}$ \\
\hline $\begin{array}{l}\text { African American } \\
\text { males }\end{array}$ & $35 \%(7 / 20)$ & 1.86 & $0^{*}$ \\
\hline
\end{tabular}

*Tinnitus was heard immediately and during the entire 20-minute session of silence.

a form and was asked to record the perception of any sounds heard during the silence. On the form, common sounds that were listed included buzz, roar, heartbeat, whistling, hum, running water, pulsing, hiss, ring, crickets, whizzing, "no sound," and other. Additional space on the form was provided for participants to further record their experience, including the point of onset and elaboration of any sounds heard.

\section{Data Analysis}

Statistical analysis was carried out using SPSS for Windows and SAS. The presence of tinnitus after silence was analyzed using Pearson X2 and univariate statistics in SPSS. Percentages and descriptions of various tinnitus sounds were determined for each gender and race subject group.

\section{RESULTS}

\section{Incidence of Tinnitus}

The incidence of tinnitus in young subjects with normal hearing is shown in Table 1. Overall, tinnitus was perceived in 77 of $120(64 \%)$ normal hearing listeners after a period of 20 minutes of silence. This study showed that 39 of 60 (65\%) female listeners and 38 of $60(63 \%)$ male listeners heard tinnitus in silent conditions. There was no significant gender difference in tinnitus 
perception in silence $\left(\mathrm{X}^{2}=0.036, \mathrm{df}=1, P=0.849\right)$. In contrast, tinnitus was perceived more commonly among Caucasian listeners (78\%) than African American listeners (38\%). This difference was significant $\left(\mathrm{X}^{2}=22.199, \mathrm{df}=1, P<0.001\right)$.

All listeners hearing tinnitus reported that it was perceived very early (less than 4 minutes into the 20- minute session of silence in the test booth). Male listeners perceived tinnitus sooner than females, and African Americans heard it sooner than Caucasians. All

Table 2. Types of tinnitus sounds heard by subjects in silence

\begin{tabular}{lccccc} 
Sound & $\begin{array}{c}\text { Caucasian } \\
\text { females }\end{array}$ & $\begin{array}{c}\text { Caucasian } \\
\text { males }\end{array}$ & $\begin{array}{c}\text { African } \\
\text { females }\end{array}$ & $\begin{array}{c}\text { African } \\
\text { males }\end{array}$ & $\begin{array}{c}\text { Total } \\
\text { (\%) }\end{array}$ \\
\hline Buzz & 3 & 6 & 3 & 4 & $16(21 \%)$ \\
Roar & 2 & 2 & 1 & 0 & $5(6 \%)$ \\
Heartbeat & 7 & 6 & 2 & 1 & $16(21 \%)$ \\
Whistling & 0 & 2 & 2 & 0 & $4(6 \%)$ \\
Hum & 7 & 3 & 1 & 1 & $12(14 \%)$ \\
Running water & 5 & 0 & 0 & 0 & $5(6 \%)$ \\
Pulse & 4 & 5 & 6 & 2 & $17(22 \%)$ \\
Hiss & 0 & 0 & 1 & 1 & $2(1 \%)$ \\
Ring & 15 & 19 & 5 & 0 & $40(57 \%)$ \\
Crickets & 0 & 3 & 0 & 0 & $3(4 \%)$ \\
Whiz & 0 & 1 & 2 & 3 & $3(4 \%)$ \\
Other & 0 & 2 & 1 & $12 / 20$ & $6(8 \%)$ \\
No sound & $9 / 40$ & $9 / 40$ & & $13 / 20$ & $43 / 120$ \\
\hline
\end{tabular}

*A total of 77 subjects heard tinnitus emerge in silence. Percentages are based on this number.

African American males $(n=20)$ heard the tinnitus immediately and throughout the entire experimental session, whereas the Caucasian females took the longest amount of time to perceive tinnitus (more than 3 minutes). Neither gender $(\mathrm{F}=2.435, \mathrm{df}=1, P=0.123)$ or race $(\mathrm{F}=1.776$, $\mathrm{df}=1, P=0.187$ ) was a significant factor in the time it took for tinnitus to be perceived. The average number of types of tinnitus sounds perceived was similar for males and females and did not prove to be statistically significant $(\mathrm{F}=2.656 \mathrm{df}=1, P=0.102)$. However, there was a significant difference in the number of sounds heard due to race $(\mathrm{F}=11.653 \mathrm{df}=1, P=0.001)$, with the African American females reporting the most number of tinnitus sounds (mean of 3 sounds).

\section{Types of Tinnitus Sounds}

Table 2 shows the types of tinnitus sounds perceived by normal hearing listeners after sitting in a relatively silent environment. Ring (57\%), buzz (21\%), pulse (22\%), heartbeat (21\%), and hum (14\%) were the most common sounds heard, with "ring" being the most common overall tinnitus sound. Buzz and pulse were the most common sounds heard by African Americans, whereas ring, hum, and heartbeat were the most common sounds heard by Caucasians. Females most commonly heard ring and pulse whereas males most commonly heard ring and buzz.

\section{DISCUSSION}

The results of the present investigation reveal a varied perception of tinnitus sounds in normal hearing listeners after experiencing a period of sustained silence. The overall perception of tinnitus in the current study (64\% of all listeners) was substantially lower than that reported in the early work of Heller and Bergman, ${ }^{14}$ which was $94 \%$ overall. There are two possible explanations for this difference. First, one factor might the difference in subject ages and the 
possible presence of some undetected mild hearing loss in older subjects. Subjects in the present study were young adults between 18 and 30 years with normal hearing sensitivity. Heller and Bergman study used 80 participants between the ages of 18 and 60 years with "self-reported" normal hearing sensitivity. It is possible that older subjects (between 30 and 60 years) in the Heller and Bergman group might have had some undetected mild hearing loss, especially in the higher frequencies, and that the higher tinnitus perception in those subjects was partly linked to age and the presence of mild hearing loss.

A second reason for the lower percentage of subjects perceiving tinnitus in the current study may be due to racial differences. The current study found a significant difference in the perception of tinnitus between Caucasian and African American listeners, with a significantly lower number of African Americans perceiving tinnitus. The Heller and Bergman study did not report differences in tinnitus due to race; however, in a personal communication from Dr. Moe Bergman, Dr. Bergman indicates that their study did have a subject pool with a mixture of races, which included some African Americans. Dr. Bergman also indicated that there were some Hispanic subjects in their study. However, this variable was not controlled for or reported in their findings. Few studies have examined racial differences in the perception of tinnitus. Cooper ${ }^{15}$ reported tinnitus being worse in African Americans.

Some studies looking at hearing acuity differences due to race have shown poorer thresholds in Caucasians than African Americans. In an early study by Bunch and Raiford, ${ }^{16}$ African American males had better high-frequency hearing than Caucasian males. Royster et al ${ }^{17}$ reported that African American male listeners with nonindustrial noise exposure history had significantly lower (better hearing) thresholds than Caucasian males with same noise exposure history. Royster et $\mathrm{al}^{18}$ reported that in adults working in industry and exposed to noise, the African American males and females continued to have lower (better) hearing thresholds than their Caucasian counterparts. In a more recent study by Pugh and Crandell, ${ }^{19}$ differences in hearing loss, hearing handicap, and functional health studies were examined between African American and Caucasian seniors. These researchers did not find any significant hearing threshold differences between African Americans and Caucasians between 500 and $4000 \mathrm{HZ}$. Caucasians did have significantly worse thresholds at $8000 \mathrm{HZ}$. These differences in hearing thresholds might contribute to the perception of tinnitus being higher in Caucasians.

In a demographic study at Gallaudet University ${ }^{2}$ the estimated prevalence of tinnitus was reported for older African American and non-African American persons in normal sound environments. The Gallaudet study estimated that for adults 55 years and older the occurrence of tinnitus was essentially the same for the 2 racial groups, being 118 per thousand in African Americans and 123 per thousand in Caucasians. However, for participants between the ages of 25 and 74 years, they reported a trend of more African Americans noticing tinnitus (302/1000) than non-African Americans (56/1000). It might be expected that a period of silence would increase the perception of tinnitus. However, the current investigation found the awareness of tinnitus even after a period of silence to be much less in African American young adults.

Additional research is needed to further identify possible differences in the perception of tinnitus due to race. This research could include study of differences in the physiology of the auditory system due to race. Such specific differences in underlying neurophysiology might help explain 
the lower tinnitus perception in African American listeners. One racial difference reported in the functioning of the human auditory system that might relate to tinnitus appears in spontaneous otoacoustic emissions (SOAEs). Whitehead et $\mathrm{al}^{20}$ has reported that SOAEs are more prevalent in African Americans than in Caucasians.

Subjects in the Heller and Bergman study were placed inside a sound booth for 5 minutes and then were asked to make notes of sounds they detected during the silent period. From these findings, Heller and Bergman con cluded, "It appears that tinnitus is present constantly but is masked by the ambient noise which floods our environment. This ambient noise level for ordinary quiet living usually exceeds $35 \mathrm{~dB}$ [referent unspecified], and apparently is of sufficient intensity to mask physiological tinnitus, which remains subaudible." In essence, these researchers concluded that all normal functioning auditory systems in humans are constantly producing a low level tinnitus that is audible only when listeners are in a sufficiently quiet environment. In subsequent studies other investigators have reported that normal hearing adults experience tinnitus in silence ${ }^{6,21}$ However, our findings do not support this conclusion that tinnitus is always present equally in all normal listeners.

Although clearly many normal-hearing participants experience the emergence of tinnitus after a period of sustained silence, the incidence of this phenomenon may not be as universal and prevalent as the earlier investigation by Heller and Bergman suggested. More research is needed to explore these factors, such as age, race, and gender, on the perception of tinnitus in normal hearing listeners.

\section{REFERENCES}

1. Noell CA, Meyerhoff WL. Tinnitus. Diagnosis and treatment of this elusive symptom. Geriatrics 2003;58:28-34.

2. Brown SC. Older American and tinnitus: a demographic study and chartbook. In: Johnson RC, Hotto SA, editors. GRI Monograph Series A No. 2. Washington, DC: Gallaudet Research Institute, Gallaudet University; 1990.

3. Alster J, Shemesh Z, Ornan M, et al. Sleep disturbance associated with chronic tinnitus. Biol Psychiatry 1993;34:84-90.

4. Folmer RL, Griest SE. Tinnitus and insomnia. Am J Otolaryngol 2000;21:287-93.

5. Dobie RA. Depression and tinnitus. Otolaryngol Clin North Am 2003;36:383-8.

6. Hazell JWP, editor. A cochlear model for tinnitus. Edinburgh: Churchill Livingstone; 1987. In: Proceedings of the III International Tinnitus Seminar. Muenster. Feldman H, editor. Karlsruhe, Germany: Harsh Verlag; 1987. p. 121-8

7. Salvi RJ, Wang J, Ding D. Auditory plasticity and hyperactivity following cochlear damage. Hearing Res 2000;147:261-74.

8. Eggermont JJ. Central tinnitus. Auris Nasus Larynx 2003;30:S7-12.

9. Jasterboff PJ. Tinnitus habituation therapy (THT) and tinnitus retraining therapy (TRT). In: RS Tyler, editor. Tinnitus handbook. San Diego: Singular Publishing; 2000. p. 35776.

10. Hazell JWP. The TRT method in practice. In: J Hazell, editor. Proceedings of the Sixth International Tinnitus Seminar. Norfolk, UK: Biddles Short Run Books; 1999; p. 92-8.

11. Cook RD, Hung TY, Miller RL, et al. Effects of conductive hearing loss on auditory nerve activity in gerbil. Hearing Res 2002;164:127-37. 
12. Tucci DL, Cant NB, Durham D. Effects of conductive hearing loss in gerbil central auditory system activity in silence. Hearing Res 2001;155:124-32.

13. Pasic TR, Rubel EW. Cochlear nucleus cell size is regulated by auditory nerve electrical activity. Orolaryngol Head Neck Surg 1991;104:6-13.

14. Heller MF, Bergman M. Tinnitus aurium in normally hearing persons. Ann Otol Rhinol Largyngol 1953;62:73-83.

15. Cooper JC Jr. Health and nutrition examination survey of 1971- 1975: Part II: Tinnitus, subjective hearing loss, and well-being. J Am Acad Audiol 1994;5:37-43.

16. Bunch CC, Raiford TS. Race and sex variations in auditory acuity. Arch Otolaryngol 1931;13:423-34.

17. Royster LH, Driscoll DP, Thomas WG, et al. Age effects hearing levels for a black nonindustrial noise exposed population. Am Ind Hyg Assoc J 1980; 41:113-9.

18. Royster LH, Royster JD, Thomas WG. Representative hearing levels by race and sex in North Carolina industry. J Acoustical Soc Am 1980;68:551-66.

19. Pugh KC, Crandell CC. Hearing loss, hearing handicap, functional health status between African American and Caucasian American seniors. J Am Acad Audiol 2002;13:493-502.

20. Whitehead ML, Kamal N, Lonsbury-Martin BL, et al. Spontaneous otoacoustic emissions in different racial groups. Scand Audiol 1993;22:3-10.

21. Vernon J. Tinnitus 1989: current knowledge and treatment therapy. Hearing J 1989;42:711. 